\title{
OHVIRA syndrome with Orofacial clefts: a rare association
}

\author{
Sambedna $^{1}$, Amit Kumar ${ }^{2 *}$, Mukta Agarwal ${ }^{1}$, Nimisha Agrawal ${ }^{1}$, Sudwita Sinha $^{1}$
}

${ }^{1}$ Department of Obstetrics and Gynecology, AIIMS, Patna, Bihar, India

${ }^{2}$ Department of Pediatric Surgery, AIIMS, Patna, Bihar, India

Received: 08 January 2020

Accepted: 01 February 2020

*Correspondence:

Dr. Amit Kumar,

E-mail: amitsandilya1981@gmail.com

Copyright: (c) the author(s), publisher and licensee Medip Academy. This is an open-access article distributed under the terms of the Creative Commons Attribution Non-Commercial License, which permits unrestricted non-commercial use, distribution, and reproduction in any medium, provided the original work is properly cited.

\begin{abstract}
Obstucted hemivagina with ipsilateral renal anomaly (OHVIRA) syndrome or Herlyn-Werner-Wunderlich syndrome (HWW) is a rare congenital anomaly consist of uterus didelphys, obstructed hemivagina, and ipsilateral renal agenesis. We are reporting an adolescent girl with orofacial defect who presented with lower abdominal pain. She attained menarche 3 months earlier and had a regular menstrual cycle with cyclical abdominal pain. On abdominal examination a firm, mobile tender mass extending from left iliac fossa up to umbilicus ( 24 weeks size) was found. Lower border of mass could not be approached. Further evaluation with ultrasound showed enlarged uterus with collection with internal echoes and non-visualization of the left kidney. CECT showed absent left kidney and didelphys uterus with large left hematocolpometra with left complex adenexal cyst. Patient was posted for hematocolpos drainage and vaginoplasty. An unusual presentation of regular menstruation and nonspecific abdominal pain delays the diagnosis, which can lead to severe complications such as endometriosis and infertility.
\end{abstract}

Keywords: Herlyn-Werner-Wunderlich syndrome, Obstructed hemivagina, Orofacial defect, Vaginoplasty

\section{INTRODUCTION}

OVHIRA syndrome, a rare variant of müllerian duct anomalies, is manifest as the triad of uterus didelphys with obstructed hemivagina and ipsilateral renal agenesis. ${ }^{1}$ Patient usually presented with cyclical abdominal pain, dysmenorrhoea and abdominal mass secondary to hematocolpos. ${ }^{2}$ It is also known as Herlyn Werner-Wunderlich syndrome. ${ }^{3}$ The first case of this syndrome was described by purslow. ${ }^{4}$

\section{CASE REPORT}

A 12-year-old girl presented to the gynae outpatient department with severe dysmenorrhoea since 3 months. She felt severe, colicky pain in the left lower abdomen with the onset of menstruation. Her pain was not radiating in nature and was not associated with fever, vomiting, or urinary symptoms. She had attained menarche 3 months earlier, cycles were regular, she used $1 \mathrm{pad} /$ day and it was associated with dysmenorrhoea and cyclical abdominal pain. She took some medication for pain relief. She was born at term with cleft lip and cleft palate. She gave history of palatoplasty (Figure 1) at 6 months of age in private hospital. She had no family history of congenital diseases. She was not sexually active and did not get any medication or hormone therapy. She belonged to a middle-class family. Her parents were non consanguineous. On general examination her weight was $37 \mathrm{~kg}$, and her height was $142 \mathrm{~cm}$ with BMI - 18.4. Her general condition was fair and vitals were stable. There was mild pallor, no icterus; no edema, bilateral breast-tanner stage 4, pubic hair and axillary hair were also tanner stage 4. On abdominal examination a 24-week size lump which was firm in consistency, mobile and tender was palpable in left iliac fossa. On perineal examination a bluish bulge was seen on left side of vagina (Figure 2). 


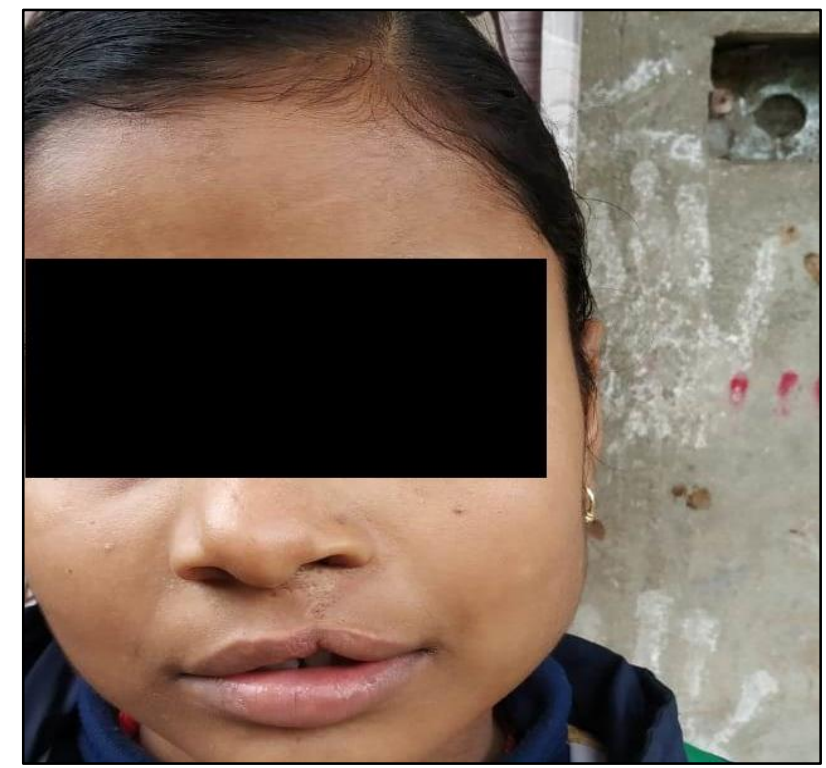

Figure 1: Orofacial defect (operated).

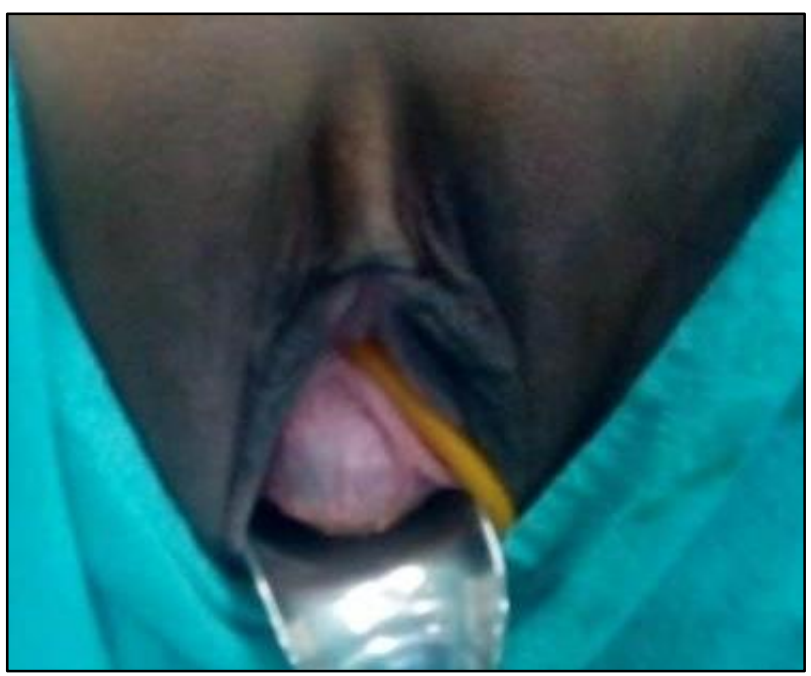

Figure 2: Bluish bulge in perineum (hematocolpos).

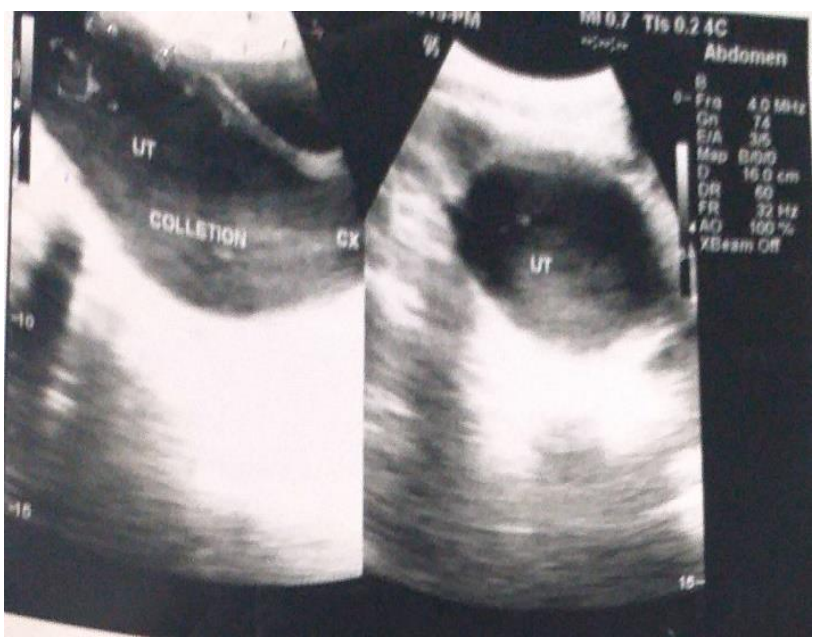

Figure 3: USG showing collection in endometrial cavity.

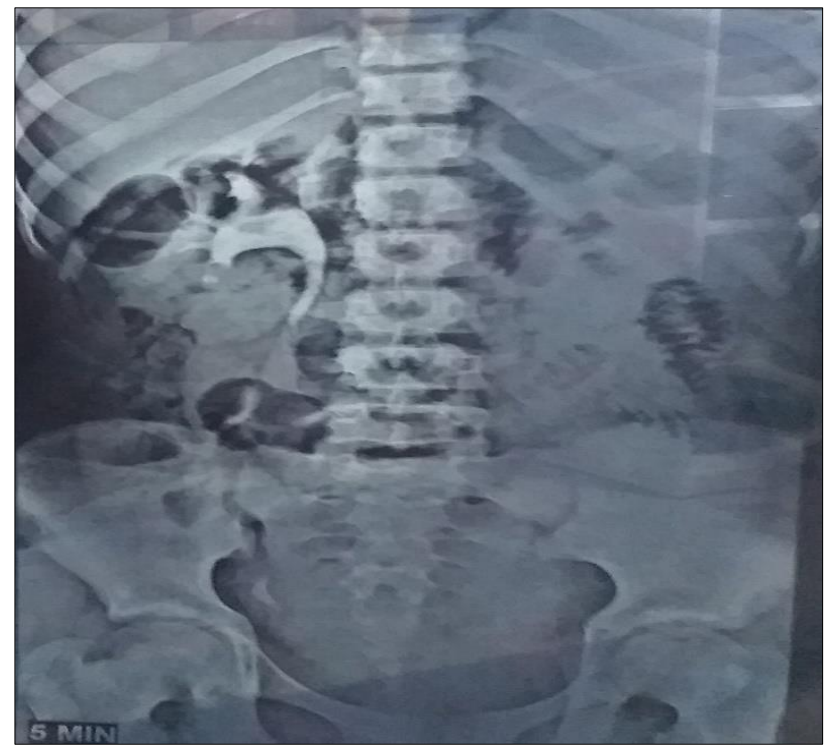

Figure 4: IVP showing absent left kidney.

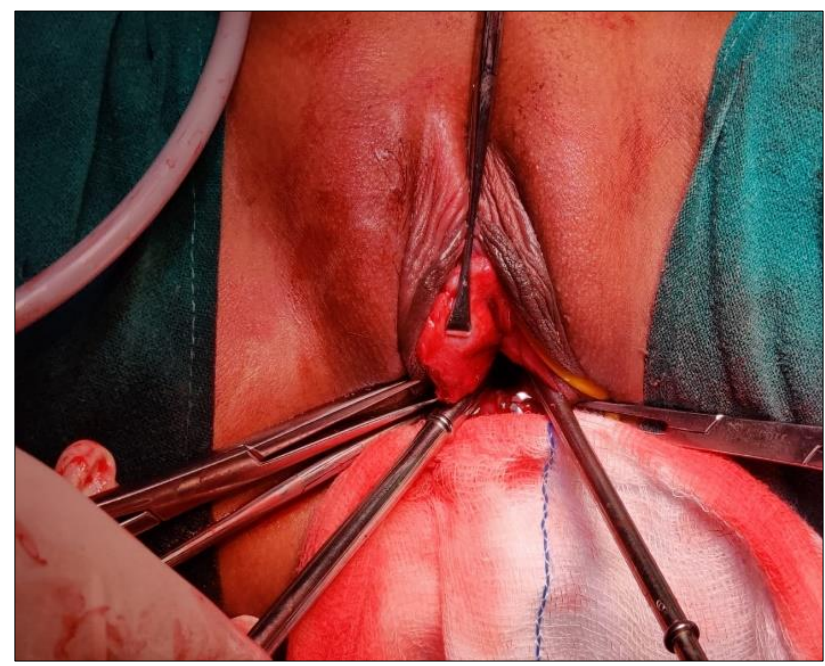

Figure 5: Intraoperative picture showing dilators in both the OS.

Per rectal examination revealed a mass in the pouch of Douglas. The patient was admitted and was planned for hematocolpos drainage and vaginoplasty. Her routine blood investigations and urine routine microscopy were within normal limits. Further evaluation with ultrasound showed distended endometrial cavity filled with complex fluid (Figure 3) with low-level internal echoes and nonvisualization of the left kidney. A provisional diagnosis of OHVIRA syndrome was made. CECT and IVP were performed for further evaluation. CECT showed didelphyus uterus with large left hematocolpometra with left complex adenexal cyst with absent left kidney. IVP revealed absent or non-excreting left kidney and normal excreting right kidney (Figure 4). Her tumor markers were within normal limit.

A cruciate incision was given on bluish bulging and tarry colored blood drained outside. Identification and resection of 
the vaginal septum were done. Both os were dilated with appropriate size of dilator and vaginal canal was reconstructed (Figure 5). There were no perioperative or postoperative complications. She was discharged on postoperative day 7 . On 1 month follow up she was menstruating normally without any dysmenorrhoea.

\section{DISCUSSION}

Uterus didelphys with obstructed hemivagina and ipsilateral renal agenesis is named as HWW or OHVIRA syndrome. ${ }^{5}$ Müllerian anomalies occur in approximately $7 \%$ of women in the reproductive age group, but the incidence of OHVIRA syndrome is still unknown. ${ }^{6}$ The mean age of presentation is $16.8 \pm 6.4(10-33)$ years. ${ }^{7}$ It is usually common in right side but in the index case it was in left side. ${ }^{8}$ It is due to anomalous development of both paramesonephric (Mullerian) and mesonephric (Wolffian) ducts. ${ }^{9}$

The Mullerian duct is displaced laterally due to absence of Wolfian duct and cannot fuse with the contralateral duct, resulting in uterus didelphys with fully developed uterine horns and two cervices. ${ }^{4,9}$ In the same setting since mullerian duct that cannot fuse with the urogenital sinus leads to an imperforate or obstructed hemivagina with longitudinal or transverse vaginal septum. ${ }^{10}$ The various literature concludes that cases can present in a multiple ways from dysmenorrhea, pelvic, or vaginal mass; abnormal vaginal discharge; acute retention of urine; fever; vomiting to infertility; complicated pregnancy; and labor or endometriosis. The most frequent symptom of OHVIRA syndrome is pain, but it can sometimes develop into pelvic inflammatory disease and abscess formation, even after menopause. ${ }^{11,12}$ Rarely, cases may be diagnosed in the newborn and infant period due to renal agenesis or muco- or hydrocolpos. ${ }^{13} \mathrm{MRI}$ is the gold standard for diagnosis. ${ }^{14}$ Definitive management of the syndrome is through vaginoplasty hysteroscopic resection of septum preserves hymen integrity. ${ }^{9,15}$ Sharma et al, reported OHVIRA syndrome with sepsis the index case is associated with orofacial defect which has not been reported in literature so far. ${ }^{16}$ The case was diagnosed early and manged promptly leading to reestablishment of regular painless menstrual cycles.

\section{CONCLUSION}

An unusual presentation of menstrual cycle with abdominal pain makes the diagnosis of OHVIRA syndrome difficult and requires special clinical suspicion. Early diagnosis is only possible by multidisciplinary approach guided by a gynecologist, radiologist, paediatrician, and pediatric surgeon is fundamental to avoid complications and ultimately it leads to better outcome

Funding: No funding sources Conflict of interest: None declared

Ethical approval: Not required

\section{REFERENCES}

1. Aveiro AC, Miranda V, Cabral AJ, Nunes S, Paulo F, Freitas C. Herlyn-Werner-Wunderlich syndrome: a rare cause of pelvic pain in adolescent girls. BMJ Case Rep. 2011;2011:bcr0420114147.

2. Piccinini PS, Doski J. Herlyn-Werner-Wunderlich syndrome: a case report. Rev Bras Ginecol Obstet. 2015;37(4):192-6.

3. Smith NA, Laufer MR. Obstructed hemivagina and ipsilateral renal anomaly (OHVIRA) syndrome: management and follow-up. Fertil Steril. 2007;87(4):918-22.

4. Purslow C. A case of unilateral haematokolpos, haematometra and haematosalpinx. BJOG Int $\mathrm{J}$ Obstet Gynaecol. 1922;29(4):643.

5. Orazi C, Lucchetti MC, Schingo PM, Marchetti P, Ferro F. Herlyn-Werner-Wunderlich syndrome: uterus didelphys, blind hemivagina and ipsilateral renal agenesis. Sonographic and MR findings in 11 cases. Pediatr Radiol. 2007;37:657-65.

6. Grimbizis GF, Campo R. Congenital malformations of the female genital tract: The need for a new classification system. Fertil Steril. 2010;94:401-7.

7. Gungor Ugurlucan F, Dural O, Yasa C, Kirpinar G, Akhan S. Diagnosis, management, and outcome of obstructed hemivagina and ipsilateral renal agenesis (OHVIRA syndrome): Is there a correlation between MRI findings and outcome. Clin Imag. 2020;59(2):172-8.

8. Tong J, Zhu L, Lang J. Clinical characteristics of 70 patients with Herlyn-Werner-Wunderlich syndrome. Inter J Gynecol Obstet. 2013;121(2):173-5.

9. Mandava A, Prabhakar RR, Smitha S. OHVIRA syndrome (obstructed hemivagina and ipsilateral renal anomaly) with uterus didelphys, an unusual presentation. J Pediatr Adolesc Gynecol. 2012;25:e23-5.

10. Troiano RN, McCarthy SM. Mullerian duct anomalies: imaging and clinical issues. State of the art. Radiol. 2004;233:19-34.

11. Capito C, Echaieb A, Loratat-Jcob S, Thibaud E, Sarnacki S, Nihoul-Fekete C. Pitfalls in the diagnosis and management of obstructive uterovaginal duplication: A series of 32 cases. Pediatr. 2008;122:e891-e897.

12. Takagi H, Matsunami K, Imai A. Uterovaginal duplication with blind hemivagina and ipsilateral renal agenesis: Review of unusual presentation. J Obstet Gynaecol. 2010;30:350-3.

13. Prada Arias M, Muguerza Vellibre R, Montero Sanchez M, Vázquez Castelo JL, Arias González M, Rodríguez Costa A. Uterus didelphys with obstructed hemivagina and multicystic dysplastic kidney. Eur J Pediatr Surg. 2005;15:441.

14. Dhar H, Razek YA, Hamdi I. Uterus didelphys with obstructed hemivagina, Ipsilateral renal agenesis and right pyocolpos: a case report. Oman Med J. 2011;26(6):447-50. 
15. Kim TE, Lee GH, Choi YM, Jee BC, Ku SY, Suh $\mathrm{CS}$, et al. Hysteroscopic resection of the vaginal septum in uterus didelphys with obstructed hemivagina: a case report. J Korean Med Sci. 2007;22(4):766-9.

16. Sharma D, Janu MK, Gaikwad R, Usha MG. HerlynWerner-Wunderlich syndrome complicated with pyocolpos: An unusual cause of postabortal sepsis. J Gynecol Endosc Surg. 2011;2:105-8.
Cite this article as: Sambedna, Kumar A, Agarwal M, Agrawal N, Sinha S. OHVIRA syndrome with Orofacial clefts: a rare association. Int J Reprod Contracept Obstet Gynecol 2020;9:1306-9. 